\section{Exploring the scope of community-based rehabilitation in ensuring the holistic development of differently-abled people}

Shrivastava Saurabh, Shrivastava Prateek, Ramasamy Jegadeesh

Department of Community Medicine, Shri Sathya Sai Medical College \& Research Institute, Kancheepuram

\section{Abstract}

Background: Globally, it has been estimated that almost $15 \%$ of world's population live with some form of disability, of which the majority are from developing nations.

Objectives: To explore the role of community-based rehabilitation (CBR) in the health sector, identify the prevalent challenges, and to suggest measures to facilitate its smooth implementation in community.

Methods: An extensive search of all materials related to the topic was made using library sources including Pubmed, Medline and World Health Organization. Keywords used in the search included community, community-based rehabilitation, disabled, and public health.

Results: The notion of community-based rehabilitation (CBR) emerged in 1978 with an aim to improve the accessibility of disabled people to rehabilitation services, especially in developing countries, by ensuring optimal use of locally available resources. CBR programs support people with disabilities by providing health services at their doorsteps, and thus estalish strong linkage between people with disabilities and the health-care system.

Conclusion: CBR encompasses a set of interventions that are implemented for a diverse and complex group of disabled people, and thus necessitates careful planning and systematic execution for ensuring welfare of these vulnerable people.

Keywords: Community-based rehabilitation, Disabled, Public health, Rehabilitation

DOI: http://dx.doi.org/10.4314/ahs.v15i1.36

\section{Introduction:}

Challenges for the disabled

Globally, it has been estimated that almost $15 \%$ of world's population (viz. $>1$ billion) live with some form of disability, of which approximately 100 million are in from the age group of $<15$ years. ${ }^{1}$ Being the largest among the vulnerable and disadvantaged section of the society, these disabled individuals are exposed to numerous challenges such as accessibility to health care institutions; poor infrastructure support; pessimistic attitude of health care providers; minimal educational / vocational opportunities; lack of self-belief; financial constraints; and minimal support to the family members, especially in developing countries. ${ }^{2}$ Furthermore, owing to the overburdened status of the public health

\section{Corresponding author:}

Shrivastava Saurabh

Department of Community Medicine, Shri

Sathya Sai Medical College \& Research

Institute, Kancheepuram

Telephone: +919884227224

Email: drshrishri2008@gmail.com care delivery system, ensuring rehabilitation of the disabled individuals, especially in the community-settings, is of significant public health concern. ${ }^{2}$

Rehabilitation is defined as the process of combined and coordinated use of medical / vocational/ social psychological measures for enabling individuals to attain the highest possible level of positive health and thus achieve social integration. ${ }^{3}$ The notion of commuan aim to improve the accessibility of disabled people to rehabilitation services, especially in developing countries, by ensuring optimal use of locally available resources. ${ }^{4,5}$ Thus, CBR encompasses different strategies that are implemented in collaboration with multiple sectors to empower disabled people/ their family member / community members regardless of any parameter by creating awareness, eliminating stigma, promoting social inclusion, meeting basic needs and facilitating access to health, education and vocational opportunities. ${ }^{3,6}$

\section{CBR: Scope and benefit}

Community-based rehabilitation (CBR) programs support people with disabilities by providing health servic-

\section{Community-based rehabilitation} nity-based rehabilitation (CBR) emerged in 1978 with es at their doorsteps, and thus establish a strong linkage between people with disabilities and the health-care system. ${ }^{7}$ The key activities of the CBR program comprise of organizing training sessions for the welfare of family and community members on disability; providing educational assistance and improving physical access; setting-up referral services; providing assistance (viz. financial support, assistive devices); arranging employment opportunities; and extending social \& recreational support. ${ }^{3}$ Findings of multiple studies have revealed that CBR activities are not only cost-effective, but have delivered encouraging results in increasing independence; enhancing mobility, improving communication skills; augmenting educational/vocational opportunities; influencing community attitudes positively; and in facilitating social inclusion, of disabled people. ${ }^{6,8,9}$

\section{Identified challenges in the field of CBR}

Despite the availability of evidence indicating remarkable benefits of CBR in different domains, the evaluation studies have revealed a wide range of challenges in the execution of CBR such as ambiguity surrounding the concept ${ }^{5}$ uncertainty about the methods by which its implementation can be fostered in community; ${ }^{5} \mathrm{im}$ plementation of similar CBR framework without customizing it to the local settings; ${ }^{10}$ absence of any inbuilt mechanism to ensure evaluation of the strategy; ${ }^{10}$ limited availability of resources ${ }^{11}$ minimal participation of community owing to culturally-insensitive nature of the programs; ${ }^{12}$ shortage of health care workers to exercise CBR $;{ }^{13}$ untrained CBR workers; ${ }^{13}$ non-employmen of multi-disciplinary teams; ${ }^{11}$ and poor coordination among health care providers and systems of delivery. ${ }^{14}$ These challenges have significantly threatened the implementation and the sustainability of CBR programs.

Recommended strategies to counter the barriers In order to negate the identified barriers, there is a need to have a strong leadership to facilitate the translation of theory into practice. ${ }^{5}$ Furthermore, adequate collaboration is required among different stakeholders (viz. policy makers, medical practitioners, health care professionals, community, and representatives from non-governmental organization) to support this intervention. ${ }^{4,}$ In addition, other interventions such as setting clear and unambiguous goals and objectives; ${ }^{4}$ building a comprehensive CBR evaluation framework (conducted in close collaboration with the local community, including people with disabilities) and testing the same for relevance appropriateness in the local settings; ${ }^{10}$ adopting combination of qualitative and quantitative methodologies to better capture the effectiveness of this strategy, ${ }^{15}$ fostering use of management information systems and monitoring: ${ }^{15}$ ensuring active community participation by designing context-specific and culture-sensitive programs ${ }^{12}$ enrolling workers from allied sectors who are skilled and willing to work for the welfare of disabled; ${ }^{1.3}$ organizing training sessions for CBR workers: ${ }^{13}$ ensuring availability of adequate resources \& establishing referral services; ${ }^{11}$ employing multi-disciplinary teams to ensure successful delivery of services in the community ${ }^{11}$ organizing formal and informal meetings between members of the team to enhance their coordination and coherence, ${ }^{14}$ and building mechanism to monitor their performance and impact on health indicators. ${ }^{13}$

\section{Conclusion}

Community-based rehabilitation encompasses a set of interventions that are implemented for a diverse and complex group of disabled people, and thus necessitates careful planning and systematic execution for ensuring welfare of these vulnerable people.

\section{References}

1. World Health Organization. World report on disability. Geneva: WHO Press; 2011.

2. Shrivastava SR, Shrivastava PS, Ramasamy J. Differently-abled children striving to lead a normal life - What program managers can do? Global J Med Res 2014; 14(1): 7-9.

3. Park K. Textbook of preventive and social medicine. 20th ed. Jabalpur: Banarsidas

Bhanot, 2009 .

4. World Health Organization. Community based rehabilitation guidelines - Introductory booklet. Geneva: WHO press; 2010.

5. Kendall E, Muenchberger H, Catalano T. The move towards community-based rehabilitation in industrialized countries: are we equipped for the challenge? Disabil Rehabil 2009; 31(26): 2164-2173.

6. Diaz-Aristizabal U, Sanz-Victoria S, Sahonero-Daza M, Ledesma-Ocampo S, Cachimuel-Vinueza M, Torrico M. Reflections on community-based rehabilitation strategy (CBR): the experience of a CBR program in Bolivia. Cien Saude Colet 2012; 17(1): 167-177.

7. World Health Organization. Community based re- 
habilitation guidelines - Health component. Geneva: WHO press; 2010.

8. Mannan $\mathrm{H}$, Turnbull A. A review of community based rehabilitation evaluations: Quality of life as an outcome measure for future evaluations. Asia Pacific Disability Rehabilitation Journal 2007; 18(1): 29-45.

9. Velema JP, Ebenso B, Fuzikawa PL. Evidence for the effectiveness of rehabilitation in the community programmes. Lepr Rev 2008; 79(1): 65-82.

10. Chung EY, Packer T, Yau M. When East meets Wests: community-based rehabilitation in Chinese communities. Disabil Rehabil 2011; 33(8): 697-705.

11. Hartley S, Gcaza S, Batesaki B, Ngomwa P, Soumana $Z$, Were $P$, et al. Comments of the community-based rehabilitation Africa network regarding the special report from the international rehabilitation forum. $J$ Rebabil Med 2010; 42(2): 187-189.
12. Pollard N, Sakellariou D. Operationalizing community participation in community-based rehabilitation: exploring the factors. Disabil Rehabil 2008; 30(1): 6270.

13. Mannan H, Boostrom C, Maclachlan M, McAuliffe E, Khasnabis C, Gupta N. A systematic review of the effectiveness of alternative cadres in community based rehabilitation. Hum Resour Health 2012; 10(1): 20.

14. La Cour K, Cutchin MP. Developing community based rehabilitation for cancer survivors: organizing for coordination and coherence in practice. BMC Health Serv Res

2013; 13: 339.

15. Grandisson M, Hebert M, Thibeault R. A systematic review on how to conduct evaluations in community-based rehabilitation. Disabil Rehabil 2014; 36(4): 265-275. 